\title{
Lapurdum
}

Euskal ikerketen aldizkaria | Revue d'études basques |

Revista de estudios vascos | Basque studies review

$20 \mid 2017$

Numéro $X X$

\section{Artxibora itzultzearen garrantziaz: Maria Angela de Txakartegiren 1775eko Mutrikuko gutuntxoa}

\section{Ekaitz Santazilia}

\section{OpenEdition}

\section{Journals}

Édition électronique

URL : https://journals.openedition.org/lapurdum/3584

DOI : 10.4000/lapurdum.3584

ISSN : 1965-0655

Éditeur

IKER

Édition imprimée

Date de publication : 1 janvier 2017

Pagination : 271-281

ISBN : 978-2-95534-135-3

ISSN : $1273-3830$

Référence électronique

Ekaitz Santazilia, «Artxibora itzultzearen garrantziaz: Maria Angela de Txakartegiren 1775eko

Mutrikuko gutuntxoa», Lapurdum [Linean], 20 | 2017, Sarean emana----an 01 janvier 2021, kontsultatu

03 septembre 2021. URL: http://journals.openedition.org/lapurdum/3584 ; DOI: https://doi.org/

10.4000/lapurdum.3584

Creative Commons - Attribution - Pas d'Utilisation Commerciale - Pas de Modification 4.0 International - CC BY-NC-ND 4.0 


\section{Artxibora itzultzearen garrantziaz: Maria Angela de Txakartegiren 1775eko Mutrikuko gutuntxoa}

Ekaitz SANTAZILIA

UPNA/NUP, UPV/EHU

\section{Aitzin solasa ${ }^{1}$}

Gero eta gehiago dira, ezinbestean, ezagutzen ditugun euskarazko testu zaharrak: hizkuntzalaritza historikoak datu iturri duen corpusa, hartara, gero eta zabalagoa, gero eta anitzagoa da. Ez nuke aipatu gabe utzi nahi, gainera, azken urteetan ezagutzera eman diren testu horiek -edo dagoeneko ezagunak zirenek-, transkribatze hutsetik haratago, edizio eta azterketa sakona izan ohi dutela lagun gaurko argitalpenetan. ${ }^{2}$ Azken urteetan ezagutu ditugun testuen edizioen artean, zilegi bekit gogora ekartzea Lazarragaren eskuizkribua (Bilbao et al. 2012), Lubietaren hiztegia (Bilbao 2011), Kadet eta Bettiriño (Padilla 2011), Zuberoa eta Erronkariren arteko gutuneria (Bilbao et al. prestatzen), Materraren dotrinaren 1617ko lehen edizioaren aurkikuntza (Ariztimuño et al. 2015) edo lerro hauen bidez laudatu nahi dugun hizkuntzalariak aski ongi ezagutzen duen Le Dauphin ontziko gutuneria (Lamikiz, Padilla \&

1. Lan hau UPV/EHUko Euskararen Historia eta Hizkuntzalaritza Historiko-Konparatua (GIC 10/83, IT 486-10) ikerketa-talde kontsolidatuaren barnean kokatzen da, Hizkuntzalaritza Teorikoa eta Diakronikoa: Gramatika Unibertsala, Hizkuntza Indoeuropeoarrak eta Euskara (HiTeDi) (UFI 11/14) Prestakuntza eta Ikerketa Unitatearen baitan. Eskerrak, orobat, "La Caixa"-k diruz hornitutako Nafarroako ondare ez-materialaren Artxiboaren Katedrari (30.31.10.3654). Eskerrak eman nahi dizkiet Teresa Alzugaray Iruñeko Elizbarrutiko Artxiboaren arduradunari emandako laguntzagatik, eta Borja Ariztimuño, Oxel Uribe-Etxebarriari eta Eneko Zuloagari, testu honi egindako iruzkinengatik. Ez dezaket ahantz Aziti Bihia Elkartearen akuilu etengabekoa.

2. Gogora dezagun Meilleten aipu ezaguna: "Pour déterminer les états de langue du passée, le linguiste doit se servir de la philologie la plus exacte, la plus précise: et chaque progrès dans la prècision philologique permet un progrès nouveau pour le linguiste" (Meillet apud Lakarra 2006: 235, etzana nirea) 
Videgain 2013). Bestalde, testu ezagunak izan arren, berriki edizio sakona izan dute Alphonsa Rodriguezen liburuak (Camino 2013) eta Axularren Gerok (Urgell 2015).

Arestian aipatuek uste dut aski ongi erakusten duten filologia gero eta zorrotzagoa dela metodoetan eta sakonagoa analisi eta ondorioetan, eta beraz, ez gabiltzala okerreko bidetik Meilleten "prècision philologique" hori lortze aldera.

Baina gauzak ez dira beti horrela izaten; zenbaitetan testu zaharren aurkikuntzaren sukarra, ezezaguna zen hori ahal bezain zale denendako eskuragarri jartzeak dakarren plazer, lana eta denbora eskatzen duen edizioaren kaltetan doa. Eta hala jokatu ohi da testu ugari batera eman nahi direnean. Argitu nahi nuke ez ditudala, adibide pare bat hautatzeagatik, J. M. Satrustegiren (1987) testu zaharren bilduma edo F. Maiorarena (2011) inondik ere arbuiatzen. Azterketa linguistikotik eta irizpide filologiko garbietatik urrun egonik ere, haiei zor diegu hurrenez hurren, beste batzuen aurkikuntzak bildu eta transkribapen aski egokien bidez ezagutzera eman izana, eta urteetako arakatze eta biltze eten eta eskergabearen emaitza den bilduma bikaina. Ezin ukatuzkoa da ikerketarako corpusari kolpean egin dioten ekarpenaren garrantzia, nahiz eta TAV edo ConTAV-en estilotik urrun xamar egon.

Baina horrelako edizioek, irizpide eta azalpen filologiko handirik gabeek, badute gutxitan aipatzen den ordaindu beharreko saria. Nire ustez, neurri batean, "erre" egiten dituzte testuak: ezagunak diren unetik eta testuaren aurkikuntzaren xarma galduta, edizio kritiko eta linguistiko sakona egiteko zain dauden testuen errenkan gibel egiten dute zenbait postu. Berehalako interesa galtzen dute filologoentzat, anitzez ere eskergabekoagoa baita beste batek ezagutzera emandakoa lantzea, aurkikuntza bera egitea baino: eta oso testu esanguratsua ez bada, edo edizioak huts nabarmenegirik ez badu, ${ }^{3}$ nekez joko du filologoak iturrietara; aski izaten du dagoeneko argitaratu den horrekin.

Lerro hauetan artxibora edo bibliotekara, testuen iturrietara, itzultzeko deia egin nahi dut. TAV-ek berak egungo ezagupenen eta irizpideen arabera dagoeneko berrikuspena merezi badu, zer esanik ez dago irizpide oker edo ezezagunetan oinarritutako edizioen kasuan, edo huts nabarmenak ageri dituzten horienetan, eta are itxuraz zuzenak diruditenetan ere. Mitxelenaren (1990 [1963]: 15-16, etzana nirea) aipu batez amaitu nahi nuke aitzinsolas hau:

(1) "Para dedicarnos con tranquilidad a la prehistoria, habremos pues de esforzarnos en adquirir el conocimiento más exhaustivo posible de los datos disponibles, sin dejar ninguno de lado y sin ahorrarnos molestias en buscarlos $y$ comprobarlos"

Gaur hona dakargun testuak artxiboetara itzuli behar horren erakusle izan nahi du. Ez gara historian zedarri den testu handi horietariko bat ezagutzera ematera heldu. Are gehiago, osoki ezezaguna denik ere ezin daiteke baieztatu; bai, ordea, hainbaten begien aurretik oharkabean pasa dela.

3. Monumenta Linguae Vasconum taldeak bidean duen Lazarragaren eskuizkribuaren edizioa (Bilbao et al. 2012) izan liteke testuaren garrantziak eta aurreko argitalpenen izaerak bultzatutako edizioaren adibide horietarik. 


\section{Testua}

\subsection{Sarrera eta testuingurua}

Iruñeko Elizbarrutiko Artxiboa datu iturri alimalekoa da Nafarroa eta Gipuzkoaren zati bat barne hartzen duen diozesiaren historia txikia ezagutzeko (cf. Sales 2004). Baina hori ez zatekeen posible, urte luzez artxibozain izan den Jose Luis Sales Tirapuren (Arlegi, 1932) eta bere laguntzaile Isidoro Ursua Irigoienen (Biguria, 1929) lan nekaezina gabe. Salesek 1975ean hartu zuen artxiboaren ardura, eta ordutik etengabe aritu da, dokumentuak banan banan eta goitik behera irakurrita, edukiak laburtzen eta dataka, gaika, herrika edo izenka sailkatzen dituen katalogoa atontzen (Jimeno Jurio 1990). 1988an lehen alea atera zenetik, ia 40 liburuki kaleratu ditu, nahi baino gehiagotan bide azaldu zaizkion oztopoak saihestuz; eta horretan darrai, gogoz kontra erretiroa hartuta ere.

Salesek begirunea izan dio euskarari. Katalogazioan hizkuntza hori aipatu edo darabilen testu zein pasarte bat agertu zaion bakoitzean horren berri eman izan du, gaikako zerrendan euskarari dagokion sarrera eskainiz. Horri esker erraza da artxiboan gordetzen diren euskarazko testu guztiak lipar batean aurkitzea. Baina ez hori bakarrik; euskarazko lekukotasun bat topatzen zuen bakoitzean bere adiskide J. M. Satrustegiri ematen zion, argitara eman zezan. ${ }^{4}$

Eta hala izan zuen Satrustegik, agerian aitortzen ez badu ere, gaur hizpide dugun dokumentuaren berri. Arruazuarrak artxiboko prozesu batean ${ }^{5}$ jaso ziren amodiozko bertso batzuk argitaratu zituen (Satrustegi 1995). Amodio eta ezkontza fedeen arteko gorabeherek eragin zuten prozesua, eta bertso elebidun batzuk fedea emana zenetz frogatzeko baliatu ziren epaiketan. Kopla horien hiru kopia daude prozesuan jasoak: ${ }^{6}$ lehena salatzaileak frogatzat aurkeztutakoa da, bigarrena eskuz esku ibili zen bertso-papera dirudi, tamaina txikiagoko kopia baita (190 x $135 \mathrm{~mm}$ ), eskuz aski erabilia, zikina eta tolestua, haustura zenbait dituena eta letra kaskarragoan idatzitakoa; gainera ez du prozesuan dagokion tokiko orri zenbaketa errespetatzen, eta ur-markak ere desberdinak dira. Hirugarrenik eskribauak berak egindako kopia dago.

Eskaintzen dituen azalpenak gora-behera, Satrustegiren edizioa bera kontuz ibiltzekoa da: irizpiderik ez dakar inon, eta deskuiduan egindako hutsegite batzuek, lerro zenbatze okerrak edo eguzki (20) —baina egusquia (35) — grafia susmagarriak besteak beste, presazko lana salatzen dute, eta jatorrizko iturrira jotzeko beharra iradoki. Baina beste gauza batzuen artean, testuaren garrantzi ez punta-puntakoak eta dagoeneko argitaratua egoteak urrundu ditu filologoak lan horri ekitetik.

4. Ziur naiz Xarles ez dela bekaiztuko idazki honek egin nahi dion gorazarrearen puxka ttiki bat J. L. Salesekin parteka dezan eskatzen badiot.

5. Prozesuak atala, 1775. Donostia. Kutxa: 2072, 9. zkia.

6. Artxiboaren katalogoko 31. liburukian jaso zen prozesu hau (Sales \& Prada 2010: 215). Bertan oker esaten da bertsoen bi kopia baizik ez dagoela dokumentuan. 
Edonola ere, Artxibora jatorrizko testua kontsultatzera joan banintzen ere, ez naiz ni hemen edizio zuzendua eskainiko duena: beste zerbaitetara nator. Bertsoen bigarren kopiak merezi du arreta berezia, edo hobe esanda, bertso horiek jasotzen dituen orri txiki, zikin, tolestu eta hautsiak, 117. orriaren ondotik dagoenak. ${ }^{7}$ Izan ere, Salesek katalogoan edo Satrustegik bere lanean, ez dute aipatzen orritxo hori aldez aurretik erabilia eta idatzia zegoela, eta bertsoak kopiatzeko berrerabili zela. ${ }^{8}$ Hartara, bertsoen ginberreko aldean ere bada zerbait idatzirik, baina jatorrizko testua aurrean izan zutenek deus aipatu ez baitzuten, ahanzturara kondenatua zegoen, inor bertso horien edizio berria egitera ausartu arte bederen. Dokumentua ikusi nuenean ohartu nintzen ginberreko testuaz, eta hori ere euskaraz dago. ${ }^{9}$

\subsection{Egilea eta testuaren ezaugarriak}

Esan bezala, bertsoak kopiatzeko orria berrerabili zutela ematen du. Testua iraulia dago bertsoen aldearekiko, eta edukiak ez du inolako zerikusirik bertsoekin, darabilten hizkerarekin, edo prozesuarekin berarekin ere.

Eskuizkribua gutuntxo labur bat da, baina dagokion testuingurutik at dagoenez, ez da erraza bertan esandakoa ongi ulertzea eta testuingururatzea. Ematen du aurretik datorren gai batez mintzo direla bertan (cf. Escribitu nion lengo correoan nola...). Zorionez, gutuna sinatua dago, data eta herriaren izena dakartza, eta baita nori zuzendu zitzaion ere.

Laburra da emakumeek idatzitako euskal testu zaharren zerrenda, eta honako testua, modu apalean bada ere, errolda hori hedatzera dator. Idazkiaren egilea emakumea da eta Theresa Angela de Chacartegui izenpetu zuen gutuna. Pedro de Ugartemendia delakoari igorri zion eta Mutrikun 1775eko martxoaren 31n sinatu zuen. ${ }^{10}$ Ezer gutxi dakigu idazleaz: Baliteke Mutrikukoa bertakoa izatea abizenari so, badakigulako 1749an Theresa Angela Baptista Echacartegui Basurco delako emakume bat bataiatu zutela Mutrikuko elizan, ${ }^{11}$ baita Josseph Antonio eta Francisco Xavier Chacartegui Bassurco (edo Basurto) izeneko bi gizon ere 1741 eta 1742. urteetan, ${ }^{12}$ aurrekoaren anaiak diratekeenak. 1769an Theresa Angela de Chacartegui

7. Errata bat dago orrien zenbaketan, eta bi aldiz dago 117. prozesuan. Aztergai dugun orritxoa bien artean dago.

8. Urkizuk (2013: 53-54) bertsoak aipatzen dituenean ere ez du horren berririk ematen, eta zuzenean Satrustegiren lana baliatu zuela dirudi, iturria egiaztatu gabe.

9. Egia aitortzeko, bada prozesu hori kontsultatu duenik eta euskarazko testuaren presentziaz ohartu denik Satrustegiren lanaz geroztik. Ugaldebere eta Madinaren liburuan ([2000]) bertsoak jaso ziren berriz ere, eta horiekin zerikusirik ez duen beste testu bat ere bazela esan. Testuaren tratamendu filologikoa ez baitzen haien lanaren xede, eskaini zuten transkribapenak hankasartze larriak ditu. Ondorioz, nahiago izan dugu gurerako kontuan ez hartu.

10. Ugaldebere \& Madinak (2000) 1779ko data ematen dute. Egia da irakurketa ez dela garbia, eta agian 1773 ere uler litekeela, baina prozesua 1775ean itxi eta artxibatu bazen, badugu ante quem data garbi bat gutuna 1779koa ezin izan zitekeela ziurtzat jotzeko.

11. Donostiako Elizbarrutiko Artxibo Historikoko (DEAH) dokumentu batek darakus hori: DEAH 2617/003-01(29r).

12. DEAH 2617/002-01 (113v) eta DEAH 2617/002-01 (102r), hurrenez hurren. 
Basurco izenekoa Mutrikuko Astigarribia auzoan ezkondu zen Joseph Martin Legorbururekin; ${ }^{13}$ orobat Theresa Angela Chacartegui bat ageri da Mutrikuko elizako hildakoen erroldan 1794. urtean. ${ }^{14}$ Azterketa linguistikorako datu interesgarria da, gainera, Theresa Angela horren ama ere, Ana Maria Damiana Basurco Basabe izenekoa, Mutrikun bataiatu zutela 1713an, ${ }^{15}$ bere anai-arrebak bezala, eta Mutrikun ezkondu zela Antonio Chacarteguirekin 1738an. ${ }^{16}$ Antonio hori zestoarra zela ematen du, izan ere, Theresa Angelaren bataio agirian aita Antonio Echacartegui Echagarai dela ageri zaigu, ${ }^{17}$ eta bada Zestoa-Arroan 1709an ezkondutako Chapartegui-Echagarai senar emazte bat, ${ }^{18}$ baina ez dugu aitaren datu zuzenik topatu. ${ }^{19}$ Ezin ziurta liteke ehuneko ehunean testuaren idazlea eta hemen kokatu dugun pertsona bat bera direnik, ezta ezarri ditugun familia harreman guztiak zuzenak direnik ere, ${ }^{20}$ baina aukera hori susmoa baino gehiago bederen badela deritzot. Gero ikusiko dugunez, hizkerak ere bat egiten du Debarrokoarekin eta zehazki Debabarrenakoarekin. Usu elizaren bidea hartu izan dute idazteko kuraia hartu duten emakumeek, baina testuaren egileak darabilen idazkera azkar eta ziurrak idazteko ohitura salatzen duen arren, artxiboetan ageri den emakumea eta testuaren idazlea pertsona bera baldin badira, ezin esan daiteke oraingoan autorea moja zenik, ezkondurik agertzen baitzaigu.

Orria tolestua eta hautsia dagoenez, ez dira hitz guztiak ongi ikusten, baina luparekiko irakurketa mantsoa eginda, gutuna osorik transkribatzeko aukera izan dugu, zalantzazko irakurketa bakan batzuez landara. Luze gabe, goazen testura.

\subsection{Transkribapena}

Jatorrizko grafiari lotu gatzaizkio inongo grafemarik aldatu gabe. ${ }^{21}$ Testuaren ulergarritasunaren mesedetan, letra larria eta hitzen zein paragrafoen banaketa gaurkotu ditugu. Berrezarritako karaktereak taketen artean kausituko ditu irakurleak, eta $<\mathrm{n}>$ gainidatziak, arrunt bilakaturik. Puntuazioa gaurkotzen saiatu gara, baina edukia ulertzeak dituen zailtasunak kontuan hartuta, eskaini dugun interpretazioa ziurtzat baino, aukeratzat har dadila iradokitzen dugu.

13. DEAH 1405/001-03 (183r).

14. DEAH 2625/002-01 (118v).

15. DEAH 2617/001-01 (60r).

16. DEAH 2617/002-02 (230r).

17. Txakartegi, Txapartegi, Etxakartegi... denak dira abizen beraren aldaerak gure ustez.

18. DEAH 1355/002-04 (10r).

19 Chapartegui-Echagaray senar-emazteak 1709an ezkondu baziren, eta handik urte gutxitara seme-alabak izanen zituztela pentsatuta, Theresa Angelaren aitaren balizko jaiotza datak bat eginen luke amaren bataio datarekin (1713).

20. Edonola ere, garai hartan Zestoan, Zumaian eta Lasarten ere aurki zitekeen abizen hori.

21. Zalantza egin liteke $<$ s $>$ batzuk $<\uparrow>$ diren. Badaezpada, denak $<$ s $>$ eman ditugu. 
M[ui] señor mio:

Escribitu nion lengo correoan nola juansan amalau legua bidian an trabajacera, baña ${ }^{22}$ beraq ere naiago deu, eta neuq ere, orr trabajacia, eta ala suplicacen diot emetiq: amabost eguneco eracarrico det, eta es begui diligenciariq egin ${ }^{23}$ beste lecutara. Escribitu beguit beriala egui[n] deba[.] (? $)^{24}$ dilige [n] ciaric, edo cer eguingo dedan. Egongo nais orren respuestiaren sain.

Veror[r]en serbisari, Theresa Angela de Chacartegui.

Motrico y Marzo 31 de 1775.

Señor Francisco de Ugartemendia.

\subsection{Hizkuntza azterketa}

Aipatu dugun bezala, ez da erraza testua ulertzea, gaiak aurreko gutunetan azaldutakoaren segida irudi baitu. Ematen du Txakartegik beste norbaiten alde jokatu nahi duela Ugartemendiaren aitzinean, ez dezaten beste lanpostu batera bidal. Horretarako, Txakartegik Ugartemendiari gogorarazi nahi dio nola aurreko gutun batean azaldu zion langile horrek hamalau legoako bidea hartu zuela lanera joateko, baina berak, Txakartegi ere alde duela, nahiago zuela beste leku batean lan egin. Hori horrela, Txakartegik langile hura etorraraziko zuen hamabost egunetarako, baina bitartean langilea beste leku batera bidaltzeko inongo izapiderik ez egiteko eskatu zion Ugartemendiari. Amaitzeko, egoeraren berri eskatzen dio Txakartegik: ea izapiderik abiarazi duen dagoeneko, eta ea zer pauso eman behar duen.

Berorika zuzentzen zaio emakumea gutunaren hartzaileari, eta horrek ere oztopatzen du, neurri batean, testuaren interpretazioa, ez baita beti lan arina jakitea hirugarren pertsonan dauden aditz eta erakusleek langilea edo Ugartemendia duten indizekide.

22. Bana ere izan liteke, izan ere sudurkariaren grafeman marratxorik baden edo ez aski zalantzazkoa da. Hala ere ez dugu uste bana aldaeraren distribuzioa bat datorrenik testu honen kokapenarekin. Mutrikun debar batek baia idatzi zuen 1695ean (Satrustegi 1987: 31-34).

23. Aurreraxeago eguingo dago. Nire aburuz, hitza lerro bukaeran eta paperaren mugan egoteak baldintzatu duke $<$ u $>$-rik ez agertzea, $<$ n $>$ ere doi-doi eta erdi gainidatzirik sartu baita.

24. Gure ustez grafema bat falta da, eta $<\mathrm{n}>$ behar du (cf. beherago dedan). Horretarako espazioa badago, baina papera urratua dago zati horretan eta luparekin begiraturik ere, ezin da ziurtatu inoiz $<$ n>-rik egon den. Aski irakurketa gaitza du hitz honek. 
Testuak mendebal-erdialdeko ezaugarri zenbait ditu, eta Mutrikuko edo Debarroko testua dela ontzat emateko hainbat arrazoi daude. ${ }^{25}$ Goazen horien berri ematera. ${ }^{26}$

Fonetikaren alorrean, respuestiaren adibidean ikus daitekeen $a+a>e a$ disimilazioa da aipagarriena. Zuazok (2006: 55, 59) Bizkaia osoan, Araban eta Gipuzkoaren zein Nafarroaren zati batean lekukoturik dugula diosku, eta Debarroan Milia Lasturkoaren eresian (TAV \& 3.1.5) badago, baita Debako gutunean 1695an ere (Satrustegi 1987: 31-34), beraz bat dator ezaugarri zabal hau testu honen ustezko kokapen geografikoarekin. Adibide horri berari trabajacia, bidian eta beriala gehituta, ea > ia disimilazioa ere sistematikoa dela ikus daiteke. Debarro osoan ohikoa da disimilazio hau gaur egun, baina Barrutiaren XVIII. mendearen lehen erdiko testuan ez da beti gertatzen; bai, ordea, mende horren bigarren erdiko Eibarko udaleko agirietan (Zuazo 2006: 58). Ez dago bokalarteko epentesirik, bide batez (cf. naiago), aipatu udaleko agirietan (Trebiño 2001) edo gaur egun Debarro osoan bezala (Zuazo 2002: 55). * edun erroko aditzetan au > eu gertatu da, deu (< dau) edo dedan (<*da-du-da-n, cf. Mitxelena 1990 [1961/1977]: 102, Ariztimuño 2013: 413) adibideek agertzen dutenez. ${ }^{27}<$ s> grafema erabili da usu bizkarkari frikarirako, eta pentsa liteke txistukarien neutralizazioa ere iritsi dela testu honetara, baina cer hitzaren salbuespenezko grafiak ez diezaguke utz asimilazioa osorik hedatu dela baieztatzen. Antza denez, neutralizazioaren hedadura kronologiko eta geografikoa aski gorabeheratsua da (cf. Hualde 2010, Zuloaga \& Atutxa 2014); esate baterako, 1685ko Eibarko kopletan (Lekuona, López de Luzuriaga \& Narbaiza 1992) edo XVIII. mendeko udal agirietan (Trebiño 2001) badugu, baina ez da sistematikoa. Bestalde, eremuan gaur egunean ohikoak badira ere, bakan dira bustidura automatikoak testuan, baña izanik adibide bakarra, egiazko adibide bada. Ez dugu ez ondoko herskarien ahoskabetzerik ere (cf. esbegui). Zuazok (2002: 52) egun ere Debarroko arkaismotzat dituen arren, ez da hasperena galdu izanaren ondorioz sortutako bokal luzerik (cf. lengo).

Izenordain eta erakusleen sailean, berorikako Verorren formaz gain, emetiq aldaera aipa daiteke, sudurkaririk gabe mendebaleko berrikuntza bat dena Mitxelenarentzat (1972: 315); hamen erakoak oso berritzat ditu OEH-k (s.v. hemen), baina lehen agerraldia Debarroan kokatzen du. ${ }^{28}$ Gisa berean, emetik bizkaitartzat badu ere, emeti aurki daiteke Gipuzkoako bizkaieraren eremuan (OEH s.v. hemendik), ez gure testuan, baina.

25. Testuak kokaleku bat eta data bat ematen digu. Hartara, testu fidagarri samarra dirudi, baina ezin atzendu daiteke ezin dela osoki ziurtatu idazlea mutrikuarra zenetz, eta are gehiago, hizkera hartzailearenera moldatu zuenetz. Mutrikuko garai bertsuko idazkirik ez dugun artean, ezin da kontua ziurtasun osoz ebatzi (cf. arazo hauetaz Camino 2009: § 18.2).

26. Zuazok (2006: 42 hh.) azaltzen duenez, Mutrikuko euskarak ez du gaurko egunean beti Debarrokoarekin bat egiten, eta gauza batzuetan erdialdeko hizkerekin batera doa. Testu honek XVIII. mendean ere halako zerbait gerta zitekeela iradokitzen du.

27. Eneko Zuloagak ohartarazi didanez, ezaugarri honek testua Gipuzkoara lerratzen du, deuBizkaiera zaharrean Zumarragak (Tovar, Mitxelena \& Otte 1981) baizik ez baitu. Egia esan, adibide bakarra du; deue (21), eta gainontzean dau eta dot darabil.

28. hemen-en etimologia *hau-en bada (Trask 1997: 211), lehen begi kolpean bitxia irudi lezake - $a$-dun formak berriagoak izatea -e-dunak baino, baina gogoan har amen formaren etimologia *ha-emen dela (cf. Mitxelena 1979: 385 hh.). 
Deklinabidean, adlatiboa dugu aditz izenean mugimenduzko aditzarekin (cf. juansan (...) trabajacera) mendebalderago inesiboa kausitzen den lekuan, Debarroan egun ere adlatiboa dago, bereziki Debabarrenean (Zuazo 2002: 38, 2006: 77). Horrekin batera, amabost eguneco gure ustez adlatiboaren gainean eraiki gabeko destinatiboa dateke.

Aditzak du esatekorik gehien. Adizki laguntzaileen erroei dagokienez, -i(n)- baizik ez dugu, eta ez eutsi, nion eta diot formek salatzen duenez, eta gaur egungo Debabarrenean espero bezala (Zuazo 2002: 48-49, 2006: 82). ${ }^{29}$ Orobat, aginterarako ez dugu *ezan aurkituko, egin baizik (cf. begui eta beguit), Debako gutunean bezala (Satrustegi 1987: 31-34). Aipatzekoa da testua idatzi zenerako * ezan erroa desagertu dela, baita forma iragankor bipertsonaletatik ere, begui (Hark-Hura) formak salatzen duenez (cf. honen kronologiaz Lakarra 1996: \& 2.3, Padilla 2013: § 8.5). Indikatiboan, *edun erroko adizkiek polimorfismo interesgarria darakuste (cf. Mitxelena 1990 [1961/1977]: 98): subjektua 3. pertsona dutenean, -eu bokal bilkura gorde da (cf. deu $<* d a-d u$ ), baina soildu, ondoren herskari bat dagoenean, det / dedan ( $<* d a-d u-d a-(n)$ ) —eta ustezko deban horretan ere bai, hala bada— adizkietan ikus daitekeenez. ${ }^{30}$ Testuak ageri duen, deu det (vs dot) banaketak bat egingo luke gaur egun Deban, Mutrikun, eta Mendaron espero denarekin (Zuazo 2002: 46-47, 2006: 81), eta gisa berean, deuan det dugu XVI. menderako Deban sortutako baina Mutrikura eramandako mojaren gutunean (Satrustegi 1987: 31-34). Trabajacera aditzak txistukaria du, eta ez herskaria 冈edo egun Debarroan aurkitzen diren bestelako aukerak冈 eta hori espero da orain Debabarrenean (Zuazo 2002: 38, 2006: 90); hala zen XVI. mendean ere (cf. Satrustegi 1987: 31-34). Iraganean zan dago, mendebal eta erdialdean ohi bezala. Horrekin batera, -itu partizipioa daukagu (cf. Escribitu), eta ez -idu; honetan ere bat dator testua egun Mutrikun dugunarekin, gainontzeko Debarroaren joeraren kontra (Zuazo 2006: 89).

Lexiko eta aldaerei gagozkien. Ohikoa da euskaraz, distantzien berri emateko, legoa hitza deklinabide atzizkirik gabe ematea, ondoren alde, bide edo luze bezalakoak jarrita, inesiboan batzuetan (cf. OEH s.v. legoa). Neska ontziratuaren baladaren sartaldeko hainbat bertsiotan bosteun legoa bidean egitura bera kausi daiteke (Arejita, Etxebarria \& Ibarra 1995). Ekarri aditzaren forma arazlea da erakarri, eta 'etorrarazi' zentzua ere har dezake (cf. OEH s.v. erakarri). Dilijentzia hitzak 'izapide' edo 'eskaera' esan nahi du hemen, gure ustez. Ez dezakegu ahantz sain lekukotzen dela testuan, amaierako sudurkariarekin. Honetan mendebalarekin bat egiten du testuak, eta ez erdialdeko euskararekin (cf. OEH s.v. zain, Zuazo 2006: 69). ${ }^{31}$ Azkenik, desagun beriala aldaera Debarroan erabilia dela, besteak beste (cf. OEH s.v. berehala).

29. Zuazok berrikuntzatzat du -i(n)- eutsi erroaren aldean, baina zilegi bekigu horretan zalantza egitea. Lehen erakoak dira Deban sortutako baina Mutrikura joandako mojaren testuko aditzak ere XVI. mende hondarrean (Satrustegi 1987: 31-34).

30. Gogoratu deban horren irakurketa zalantzazkoa dela. Gainera, gaur egun ere ez dugu $u>b$ bilakaera Debagoienean baizik espero, gainontzean $u$-k iraun baitu (Zuazo 2002: 72).

31. Badira -ai erakoak mendebaleko euskara zaharrean ere, baina hitz honetan sudurkaridunak ematen du mendebaldeko aldaera arrunta (Mitxelena 1990 [1961/1977]: 143-144). 


\section{Erreferentziak}

Arejita, Adolfo, Igone Etxebarria \& Jaione Ibarra. 1995. Mendebaldeko euskal baladak. Antologia. Bilbo: Labayru.

Ariztimuño, Borja. 2013. Finite verbal morphology. In Mikel Martínez-Areta (arg.), Basque and Proto-Basque: Language-Internal and Typological Approaches to Linguistic Reconstruction. 359-427. Frankfurt am Main: Peter Lang.

Ariztimuño, Borja, Udane Atutxa, Dorota Krajewska, Urtzi Reguero, Ekaitz Santazilia, Oxel Uribe-Etxebarria \& Eneko Zuloaga. 2015. Materra: edizioa eta azterketa (1.0). VitoriaGasteiz: UPV/EHU. Sarean eskuragarri: https://sites.google.com/site/materraedizioa [Kontsulta: 2015/05/03].

Bilbao, Gidor. 2011. Lubieta, izen berri bat euskal testuen historian. In Joseba Andoni Lakarra, Joaquín Gorrochategui \& Blanca Urgell (arg.), Koldo Mitxelena Katedraren II. Biltzarra. 621-650. Vitoria-Gasteiz: UPV/EHU.

Bilbao, Gidor, Ricardo Gómez, Joseba Andoni Lakarra, Julen Manterola, Céline Mounole \& Blanca Urgell. 2012. Lazarraga eskuizkribua: edizioa eta azterketa (2.0). Vitoria-Gasteiz: UPV/EHU. Sarean eskuragarri: http://www.lazarraga.com [Kontsulta: 2015/04/10].

Bilbao, Gidor, Ricardo Gómez, Joseba Andoni Lakarra, Julen Manterola, Céline Mounole \& Blanca Urgell. Prestatzen. Gabriel Echart zuberotarraren eta Miguel Ros erronkariarraren arteko gutuneria (1615-1617). UPV/EHU.

Camino, Iñaki. 2009. Dialektologiatik euskalkietara tradizioan gaindi. Donostia: Elkar.

Camino, Iñaki. 2013. "Alphonsa Rodriguez Jesusen Compagnhaco aitaren guiristhinho perfeccioniaren praticaren pparte bat (1782)": edizioa eta azterketa. ASJU 47(1). 3-486.

ConTAV = Sarasola 1983.

Hualde, José Ignacio. 2010. Neutralización de sibilantes vascas y seseo en castellano. Oihenart 25. 89-116.

Jimeno Jurio, José María. 1990. José Luis Sales Tirapu. Catálogo del Archivo Diocesano de Pamplona. RIEV 35(1). 111-113.

Lakarra, Joseba Andoni. 1996. Refranes y Sentencias (1596): Ikerketak eta edizioa. Bilbo: Euskaltzaindia.

Lakarra, Joseba Andoni. 2006. Protovasco, munda y otros: Reconstrucción interna y tipología holística diacrónica. Oihenart 21. 229-322.

Lamikiz, Xabier, Manuel Padilla \& Xarles Videgain. 2013. "Le Dauphin" itsasontziko euskarazko gutunak (1757): lehen hurbilketa. In Ricardo Gómez, Joaquín Gorrochategui, Joseba Andoni Lakarra \& Céline Mounole (arg.), Koldo Mitxelena Katedraren III. Biltzarra. 325-341. Vitoria-Gasteiz: UPV/EHU.

Lekuona, Juan Mari, José Ignacio López de Luzuriaga \& Antxon Narbaiza. 1992. 1685eko kopla zaharrak. Eibar: Ego Ibarra.

Maiora, Fernando. 2011. Reino de Navarra. Euskera: Injurias, coplas, frases. Egilearen argitalpena.

Mitxelena, Koldo. 1972. Etimología y transformación. In Homenaje a Antonio Tovar. 305-317. Madrid: Gredos.

Mitxelena, Koldo. 1979. Miscelánea filológica vasca. IV. FLV 33. 377-406. 
Mitxelena, Koldo. 1990 [1961/1977]. Fonética Histórica Vasca. Berrarg. in ASJUren gehigarriak 4. Donostia: Gipuzkoako Foru Aldundia.

Mitxelena, Koldo. 1990 [1963]. Lenguas y protolenguas. Berrarg. in ASJUren gehigarriak 10. Donostia: Gipuzkoako Foru Aldundia.

Mitxelena, Koldo. 1990 [1964]. Textos Arcaicos Vascos. Berrarg. in ASJUren gehigarriak 11. Donostia: Gipuzkoako Foru Aldundia \& UPV/EHU.

Mitxelena, Koldo \& Ibon Sarasola. 1987-2005. Orotariko Euskal Hiztegia. Bilbo: Euskaltzaindia. OEH = Mitxelena \& Sarasola 1987-2005.

Padilla, Manuel. 2011. Kadet eta Bettiriño. Bilbo: Euskaltzaindia.

Padilla, Manuel. 2013. Non-finite verbal morphology. In Mikel Martínez-Areta (arg.), Basque and Proto-Basque: Language-Internal and Typological Approaches to Linguistic Reconstruction. 323-357. Frankfurt am Main: Peter Lang.

Sales, José Luis. 2004. El Archivo Diocesano de Pamplona. Príncipe de Viana 231. 11-28.

Sales, José Luis \& Antonio Prada. 2010. Catálogo del Archivo Diocesano de Pamplona: Sección Procesos. Siglo XVIII. 31. liburukia. Iruñea: Iruñeko Elizbarrutiko Artxiboa.

Sarasola, Ibon. 1983. Contribución al estudio y edición de textos antiguos vascos. ASJU 17. 69-212.

Satrustegi, José María. 1987. Euskal Testu Zaharrak I. Iruñea: Euskaltzaindia.

Satrustegi, José María. 1995. Texto bilingüe de una canción amorosa guipuzcoana del siglo XVIII. FLV 68. 37-50

TAV = Mitxelena 1990 [1964].

Tovar, Antonio, Koldo Mitxelena \& Enrique Otte. 1981. Nuevo y más extenso texto arcaico vasco de una carta del primer obispo de Mexico, Fray Juan de Zumárraga. Euskera 26(1). 5-14.

Trask, Robert Lawrence. 1997. The History of Basque. Londres: Routledge.

Trebiño, Imanol. 2001. Administrazio zibileko testu historikoak. Oñati: HAEE.

Ugaldebere, Tomas \& Mikel Madina. [2000]. Donostiarrak eta euskara. XVI-XVIII. Mendeak. Donostia: Euskararen Udal Patronatua. Sarean eskuragarri: http://www. donostiaeuskaraz.eus/euskaraz/euskara-donostian/sekzioak/donostiarrak-eta-euskaraxvixviii-mendeak/ [Kontsulta: 2015/05/13].

Urgell, Blanca. 2015. Gero: Axular. Iruñea \& Bilbo: Nafarroako Gobernua \& Euskaltzaindia.

Urkizu, Patricio, 2013. Poesía vasca. Antología bilingüe. Madril: UNED.

Zuazo, Koldo. 1999. Deba ibarreko euskeria. Eibar: Eibarko Udala.

Zuazo, Koldo. 2006. Deba ibarreko euskara. Dialektologia eta tokiko batua. Eibar: Badihardugu Euskara Elkartea.

Zuloaga, Eneko \& Udane Atutxa. 2014. La neutralización de las sibilantes en vasco: una perspectiva diacrónica. In Felipe Jiménez, Ana Jimeno, Alberto de Lucas \& Nekane Celayeta (arg.), Variación geográfica y social en el panorama lingüístico español. Iruñea: Nafarroako Unibertsitatea. 


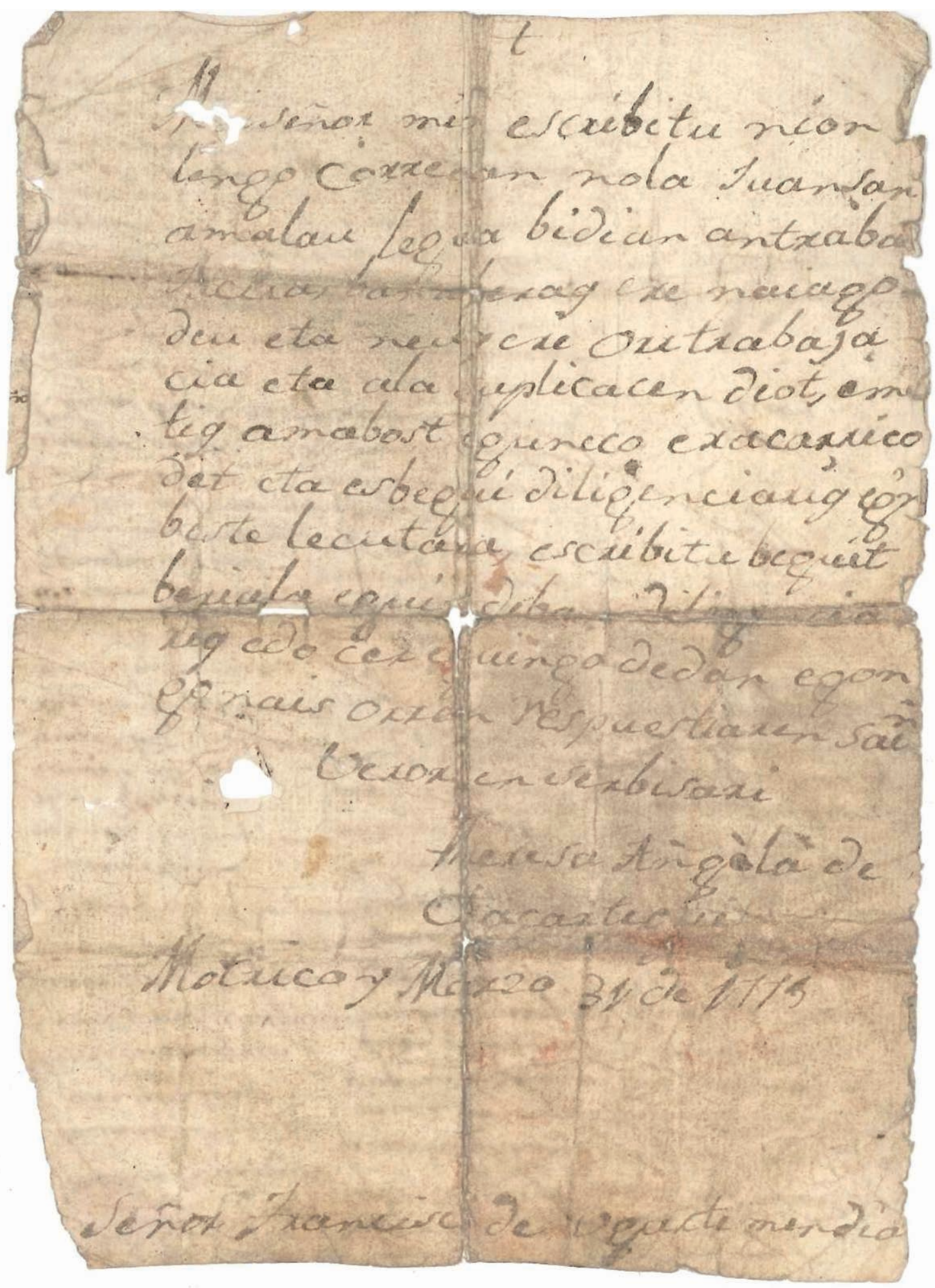

Iruñeko Elizbarrutiko Artxiboa. Prozesuak. Donostia, 1775. Kutxa: 2072, 9. zkia. 